\title{
Effects of Testosterone on the Expression of Connexin 26 and Connexin 43 in the Uterus of Rats During Early Pregnancy
}

\author{
DATU AGASI MOHD KAMAL ${ }^{1,2}$, SITI FATIMAH IBRAHIM ${ }^{1}$ and MOHD HELMY MOKHTAR ${ }^{1}$ \\ ${ }^{1}$ Department of Physiology, Faculty of Medicine, \\ Universiti Kebangsaan Malaysia (UKM), Kuala Lumpur, Malaysia; \\ ${ }^{2}$ Department of Biomedical Sciences and Therapeutics, \\ Faculty of Medicine and Health Sciences, University Malaysia Sabah, Kota Kinabalu, Malaysia
}

\begin{abstract}
Background/Aim: It was hypothesized that testosterone could affect the distribution and expression of connexin 26 and connexin 43 in the uterus. Thus, the effects of testosterone on these parameters in the uterus during the uterine receptivity period were investigated. Materials and Methods: Intact pregnant rats were administered 1 $m g / k g / d a y$ testosterone alone or in combination with flutamide, finasteride or anastrozole, subcutaneously on day1 of pregnancy till day 3. The rats were sacrificed at day 4 of pregnancy, which was considered as the uterine receptivity period for determining the expression and distribution of connexin 26 and connexion 43 by immunohistochemistry and quantitative polymerase chain reaction, respectively. Results: Treatment with $1 \mathrm{mg} / \mathrm{kg} /$ day testosterone increased connexin 26 and decreased connexin $43 \mathrm{mRNA}$ expression and protein distribution in the uterus of early pregnancy rats. Conclusion: Changes in the uterine connexin 26 and connexin 43 expression by testosterone could disrupt embryo implantation, resulting in early pregnancy loss.
\end{abstract}

Testosterone is a male sex steroid hormone that is important in female reproductive physiology. Testosterone is required in the process of embryo implantation and decidualization (1). Testosterone concentration in women shows variations with the highest testosterone concentration seen in the middle of the menstrual cycle, during ovulation (2). However, a high level of testosterone concentration could

This article is freely accessible online.

Correspondence to: Mohd Helmy Mokhtar, Department of Physiology, Faculty of Medicine, Universiti Kebangsaan Malaysia (UKM), Jalan Yaacob Latif, Bandar Tun Razak, 56000, Cheras, Kuala Lumpur, Malaysia. Tel: +60 391458619, e-mail: helmy@ukm.edu.my

Key Words: Testosterone, connexin, uterine receptivity, early pregnancy. intervene with the peri-implantation embryo and uterine development, resulting in early pregnancy loss (3).

Early pregnancy loss is usually related to defects that occur prior to, during, or immediately after implantation (4). Implantation is a highly regulated event that involves interaction between the blastocyst and the receptive endometrium, and occurs during a limited time, called the uterine receptivity period (5). The uterine receptivity is precisely coordinated by sex-steroid hormones, namely estrogen, and progesterone that modulate uterine events in a spatiotemporal manner (6). However, Grummer et al. (7) have also found that uterine receptivity is regulated by the expression of connexin 26 and connexin 43, which are protein that assemble the intercellular gap junctions that are expressed in the endometrium of rats $(8)$ and humans $(9,10)$.

Intercellular gap junction proteins constitute a membranespanning channel that permits a direct intercellular exchange of small molecules and inorganic ions between cells to mediate electrical and metabolic coupling between two adjacent cells $(11,12)$. Connexins determine the character of the intercellular junction as they regulate the ionic conduction and metabolic coupling between cells $(13,14)$. It has been reported that secondary messengers in signal transduction pathways such as cyclic AMP, amino acids, and short peptides are also able to pass through the intercellular gap junction channel (15). Therefore, the intercellular gap junction plays an important role in mediating cellular differentiation, tissue development, homeostasis and, morphogenesis (13).

Several types of connexins are expressed in the female reproductive organs, and are essential to the physiology of the female reproductive system (16). Connexin 26 and connexin 43 are expressed in the endometrium of both humans and rats, while humans also express connexin 32 (8, 9). However, only connexin 26 and connexin 43 are regulated by the sex-steroid hormones in cycling endometrium, where the expression of both connexins increases by estrogen administration and is suppressed by 
progesterone during the uterine receptivity period $(8,17)$. Furthermore, it has been reported that only connexin 26 and connexin 43 are detected in the rat endometrium during early pregnancy (18).

Uterine receptivity is impaired in polycystic ovary syndrome, which is associated with high plasma testosterone levels. A study conducted in rats has found that a high concentration of testosterone suppresses the expression of $\alpha v \beta 3$-Integrin, E-Cadherin, and Mucin-1, which are the markers of the receptive endometrium (19). However, the effects of testosterone on connexin 26 and connexin 43, which also play a role in uterine receptivity, are yet to be elucidated.

In this study, it was hypothesized that testosterone alters the expression and distribution of connexin 26 and connexin 43 , which would then interfere with uterine receptivity and lead to implantation failure. This study could help to elucidate the mechanisms underlying the adverse effect of high testosterone levels on uterine receptivity and may explain the infertility issues seen in patients with high androgen concentrations such as polycystic ovary syndrome (PCOS) patients.

\section{Materials and Methods}

Animal preparation and hormonal treatment. Adult female SpragueDawley (SD) rats, weighing $225 \pm 25 \mathrm{~g}$ that showed at least two consecutive regular cycles were used in this study. The rats were obtained from the Laboratory Animal Resources Unit, Faculty of Medicine, Universiti Kebangsaan Malaysia. The rats were kept under standardized conditions with lights on from 06:00 to 18:00 h; room temperature $24 \pm 2^{\circ} \mathrm{C} ; 1$ animal per cage. Rats were fed on chow diet (Harlan, Germany) and tap water was given ad libitum. All experimental procedures were approved by the National University of Malaysia animal ethics committee (approval number: FISIO/PP/20 18/MOHDHELMY/26SEPT/956-SEPT-2018SEPT2019). Rats in the proestrus stage were caged overnight with a male from the same species at a 1:1 ratio. The next morning, successful copulation was confirmed by the presence of a vaginal plug. This day was designated as day 1 of pregnancy (20).

Testosterone (Tokyo Chemical Industry, Tokyo, Japan), flutamide, finasteride, and anastrozole (Sigma-Aldrich, St Louis, MO, USA) were dissolved in $0.1 \mathrm{ml}$ peanut oil prior to subcutaneous (s.c.) injection behind the neck scruff.

Pregnant rats were randomly assigned into the following groups with $\mathrm{n}=6$ rats per group.

Group 1: Normal pregnant rats (C).

Group 2: Pregnant rats treated with $1 \mathrm{mg} / \mathrm{kg} /$ day of testosterone (T) (21).

Group 3: Pregnant rats treated with $1 \mathrm{mg} / \mathrm{kg} /$ day of testosterone and $5 \mathrm{mg} / \mathrm{kg}$ /day flutamide (T+FLU) (22).

Group 4: Pregnant rats treated with $1 \mathrm{mg} / \mathrm{kg} / \mathrm{day}$ of testosterone and $1 \mathrm{mg} / \mathrm{kg}$ /day finasteride $(\mathrm{T}+\mathrm{FIN})(22)$.

Group 5: Pregnant rats treated with $1 \mathrm{mg} / \mathrm{kg} /$ day of testosterone and $1 \mathrm{mg} / \mathrm{kg} / \mathrm{day}$ anastrozole (T+ANA) (23).

All rats were treated for 3 consecutive days starting from day 1 till day 3 of pregnancy (early pregnancy period) (4). All inhibitory

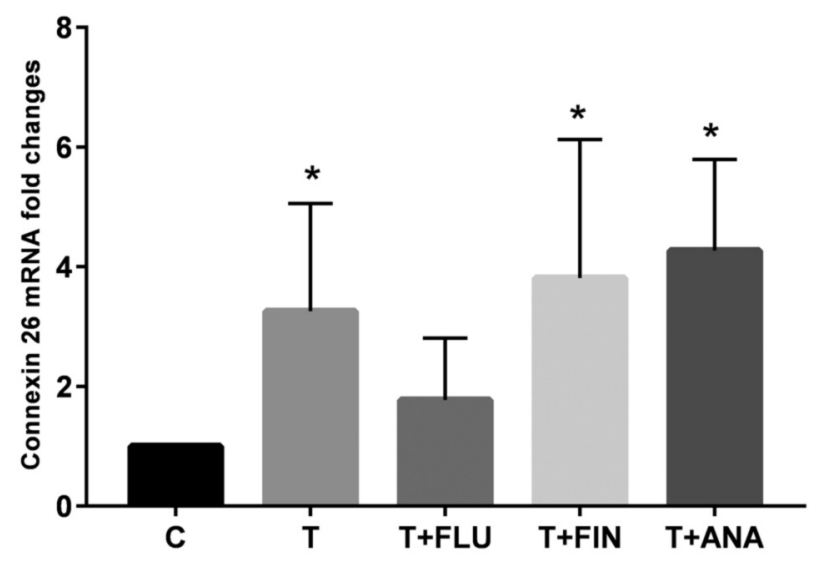

Figure 1. Levels of connexin $26 \mathrm{mRNA}$ in the uterus of early pregnant rats. In these rats, administration of testosterone alone and concomitant administration of testosterone with either finasteride or anastrozole on days 1-3 of pregnancy significantly increased connexin 26 mRNA levels. No significant change was recorded in connexin $26 \mathrm{mRNA}$ expression in rats that received testosterone and flutamide injection. C: Control; T: testosterone; FLU: flutamide; FIN: finasteride; ANA: anastrozole. Data are presented as mean \pm SEM. $n=6$ for each group. *Significant $(p<0.05)$ compared to the control group.

drugs, flutamide, finasteride and anastrozole, were injected 30 minutes prior to testosterone injection. The supraphysiological dose of testosterone used in this study was chosen based on doses previously used in other studies (21). Rats were sacrificed on day 4 of pregnancy, which is considered as the day of uterine receptivity in rats, by intravenously injecting high doses of ketamine-xylazine at $0.3 \mathrm{ml} / 100 \mathrm{~g}$. The uteri were then harvested to analyze the changes in the gene expression and distribution of connexin 26 and connexin 43 .

Protein distribution analysis by immunohistochemistry (IHC). Uteri were fixed overnight in $4 \%$ paraformaldehyde (PFD) prior to processing, dehydrated through increasing concentrations of ethanol, cleared in chloroform, and blocked in paraffin wax. Sections of 5 $\mathrm{mm}$ in thickness were prepared. Slides were then treated with antigen retrieval solution (Dako, Glostrup, Denmark) pH 6.0. To prevent endogenous peroxidase, slides were treated with hydrogen peroxide. Then, samples were incubated with blocking serum provided in the Mouse and Rabbit Specific HRP/DAB IHC Detection Kit - Micro-polymer (Cat ab236466, Abcam, Cambridge, MA, USA). To analyse the distribution of connexins, the slides were incubated with a rabbit polyclonal antibody against connexin 43 in a 1: 500 dilution (Cat AB11370 Abcam) or a rabbit polyclonal antibody against connexin 26 in a 1: 500 dilution (Cat AB65969 Abcam). The slides were then incubated with micro-polymer secondary antibody provided in the Mouse and Rabbit Specific HRP/DAB IHC Detection Kit (Cat ab236466, Abcam). To visualize the protein, the slides were incubated with $\mathrm{DAB}$ substrate provided in the Mouse and Rabbit Specific HRP/DAB IHC Detection Kit Micro-polymer (Cat ab236466, Abcam). Finally, sections were counterstained with hematoxylin and dehydrated sequentially. The slides were visualized using an Olympus BX40 light microscope (Olympus corporation, Tokyo, Japan). 

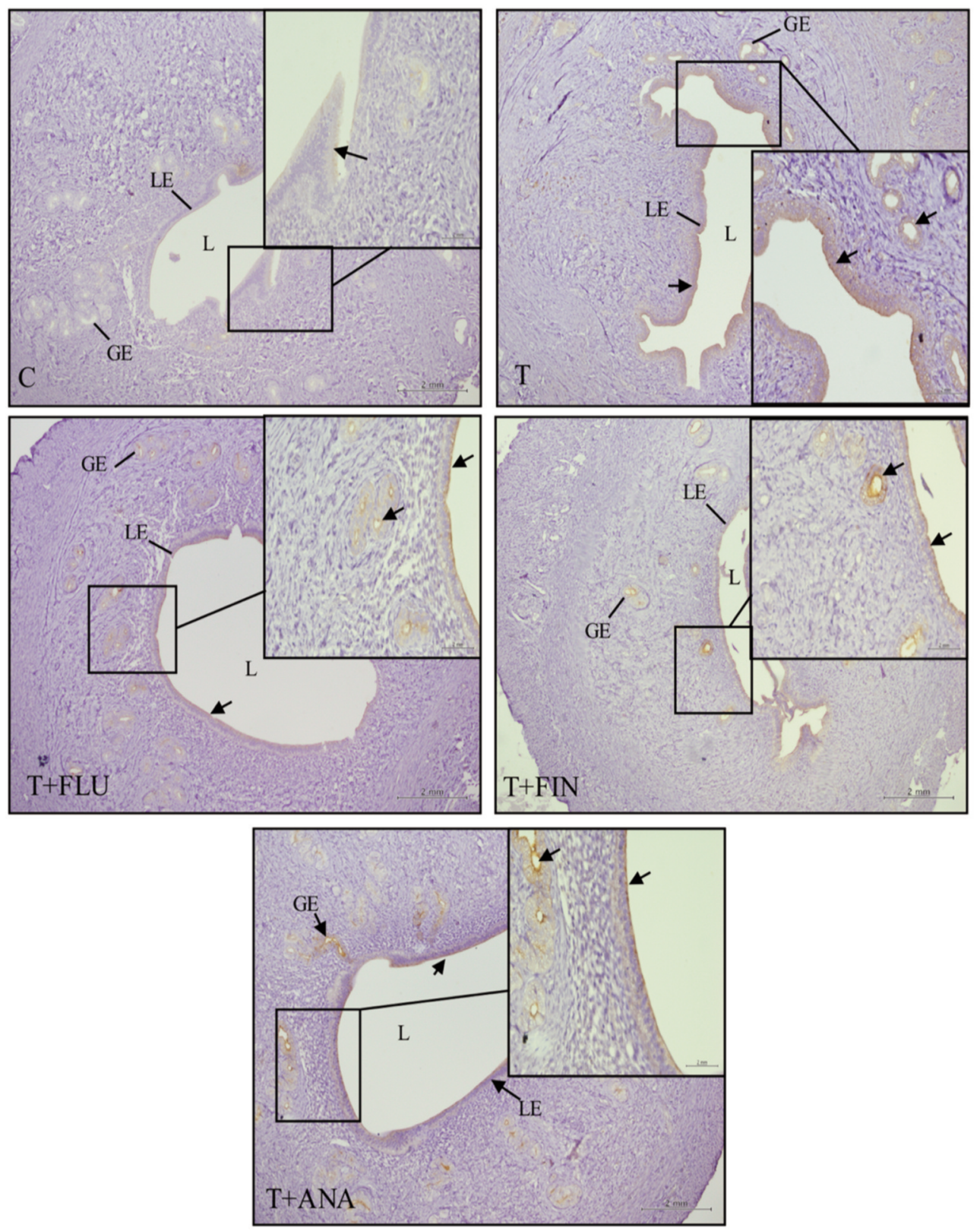

Figure 2. Connexin 26 distribution in the uterus of rats. The dark brown color pointed by arrows indicates the antibody-binding site of connexin 26 that appears to be present in the uterine luminal epithelium and the uterine gland epithelium. Strong dark brown staining was observed in the four treatment groups compared with the control group. C: Controls; T: testosterone; FLU=flutamide; FIN: finasteride, ANA: anastrozole; LE: luminal epithelium; GE: glandular epithelium; L: endometrium lumen. Scale bar=2000 $\mu \mathrm{m}$. Magnification 100x and 400x, $n=6$ per group.

Gene expression analysis by real-time PCR. Rat uteri were kept in RNA Later solution (Sigma Aldrich, Saint Louis, MO, USA) to stabilize and maintain the integrity of the RNA in the cell. RNA was extracted from the uterus using the Nucleospin RNA isolation kit (CAT 740955.50 Macherey-Nagel, Duren, Germany). The RNA extraction process was performed according to the manufacturer's protocol. Absorbance of each sample was measured at $260 \mathrm{~nm}$ and $280 \mathrm{~nm}$, and RNA purity was assessed by the 260/280 ratio (Gene Quant 1300, Cambridge, UK). Reverse transcription into cDNA was performed by using the qPCRBio cDNA synthesis kit (CAT PB30.11-10 PCR Biosystems, London, UK). Amplification of samples without the addition of reverse transcriptase (-RT) was used as a control. The qPCR master mix was prepared using qPCRBio SyGreen Blue Mix kit (CAT PB20.17-05 PCR Biosystems). Glyceraldehyde-3-phosphate dehydrogenase $(G A P D H)$ was used as a reference gene. Specific primers for connexin 43 (Rn_Gja1_1_SG Qiagen, Hilden, Germany), connexin 26 (Rn_Gjb2_1_SG Qiagen) and Glyceraldehyde-3-phosphate dehydrogenase (GAPDH) 


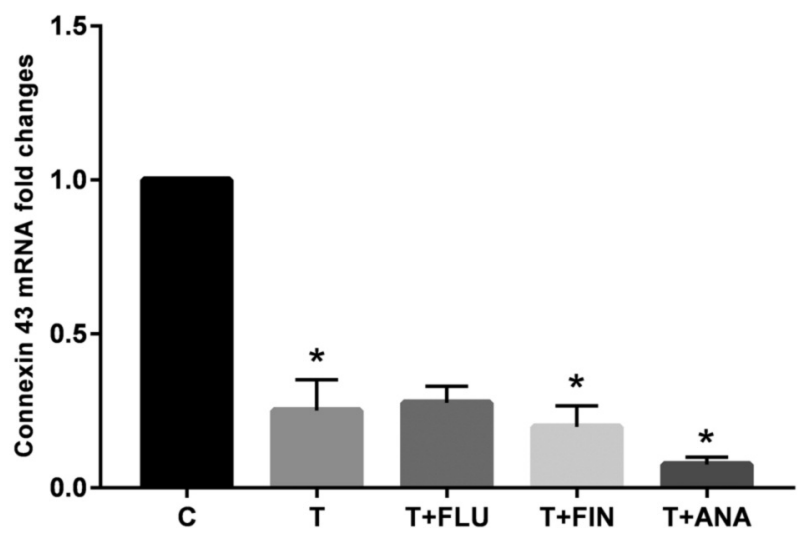

Figure 3. Levels of connexin $43 \mathrm{mRNA}$ in the uterus of early pregnant rats. In these rats, administration of testosterone alone and concomitant administration of testosterone with either finasteride or anastrozole on days 1-3 of pregnancy significantly decreased connexin 26 mRNA levels. No significant change was recorded in connexin 43 mRNA expression in rats that received testosterone and a flutamide injection. C: Control; T: testosterone; FLU: flutamide; FIN: finasteride; ANA: anastrozole. Data are presented as mean \pm SEM. $n=6$ for each group. *Significant $(p<0.05)$ compared to the control group.

(Rn_Gapd_1_SG Qiagen) were used for the qPCR. Real-time PCR was conducted by using the BioRad CFX96 Real-Time System. The conditions were as follows: $5 \mathrm{~min}$ at $95^{\circ} \mathrm{C}$ to activate the polymerase followed by $10 \mathrm{sec}$ at $95^{\circ} \mathrm{C}$ for 40 cycles for the denaturation process and $30 \mathrm{sec}$ at $60^{\circ} \mathrm{C}$ for 40 cycles for adhesion and elongation. All experiments were carried out in triplicates. Data were analyzed according to the comparative CT $\left(2^{-\Delta \Delta \mathrm{Ct}}\right)$ method. The relative quantity of each amplicon was determined by comparing the normalized quantity of each gene to the normalized quantity of each reference gene.

Statistical analysis. Data were analyzed using parametric analysis of variance (ANOVA) followed by post hoc test using Tukey test. The Shapiro-Wilk normality test was used to test the normality of data. If the data distribution was abnormal, the Mann-Whitney $U$ test was performed. The difference was considered statistically significant when $p<0.05$.

\section{Results}

Effect of testosterone on connexin 26 mRNA expression and its protein distribution. Figure 1 shows the levels of connexin 26 mRNA in the uterus. In this study, administration of testosterone on day 1 till day 3 of pregnancy resulted in a significantly increased expression of connexin 26 mRNA as compared to that in normal pregnant rats $(p<0.05)$. A significant increase was also noted in the testosterone-treated group following finasteride and anastrozole injection $(p<0.05)$. However, no significant change was recorded in connexin 26 mRNA expression in rats that received testosterone and a flutamide injection.
Meanwhile, no significant differences were observed in connexin 26 mRNA expression in rats receiving testosterone either with finasteride or anastrozole when compared to the testosterone only group.

Figure 2 shows the localisation of connexin 26 protein in the luminal and glandular epithelium of the uterus. The staining intensity increased after treatment with testosterone. Higher staining intensities were also observed after concomitant administration of testosterone with either flutamide, finasteride or anastrozole, compared to the control group.

Effect of testosterone on connexin 43 mRNA expression and its protein distribution. The mRNA expression of connexin 43 was highest in normal pregnant rat group (Figure 3). Administration of testosterone between days 1 and 3 of pregnancy caused a decrease in the expression of connexin 43 in the uterus as compared to normal pregnant rats $(p<0.05)$. A significant decrease in connexin $43 \mathrm{mRNA}$ expression was also noted in the testosterone-treated group following finasteride and anastrozole injection $(p<0.05)$. However, concomitant administration of flutamide and testosterone did not cause a significant change in connexin 43 mRNA expression when compared with the control group. Meanwhile, no significant differences were also observed in rats receiving testosterone either with finasteride or anastrozole when compared to the testosterone only group.

Immunohistochemical analysis revealed that connexin 43 was localized in the endometrial stroma of normal pregnant rats (Figure 4), Staining intensity of connexin 43 was markedly reduced following testosterone administration during the early pregnancy period. Furthermore, concomitant administration of testosterone with either finasteride or anastrozole did not result in any noticeable changes in connexin 43 distribution as compared to the testosterone only group.

\section{Discussion}

In this study, it was found that treatment with a high dose of testosterone resulted in increased expression of connexin 26 in the uterus during the early pregnancy period. Furthermore, connexin 26 was detected in the luminal and glandular epithelium of the uterus, as reported in previous studies (8, $24)$, and its staining intensity increased following testosterone treatment. Physiologically, in humans and rats, connexin 26 expression is suppressed in the receptive phase of the endometrium $(8,9)$, and the specific ratio of progesterone to estrogen strictly regulates this suppression (18). This suppression is important as it is a unique physiological condition that required to achieve endometrial receptivity period (18). Besides, an increase in connexin 26 expression 

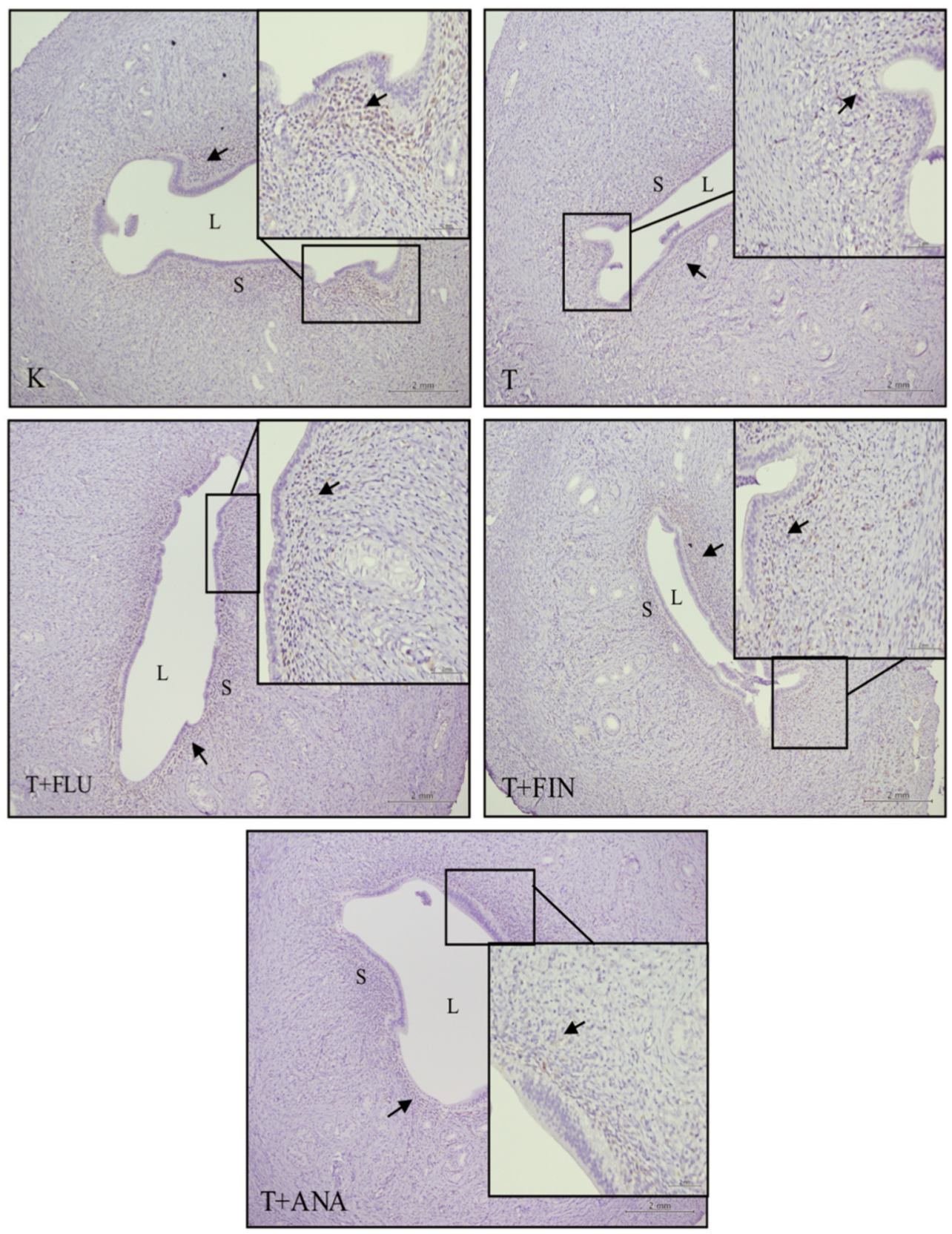

Figure 4. Connexin 43 distribution in the uterus of rats. The dark brown color pointed by the arrows indicates the antibody binding site of connexin 43 that appears to be present in the endometrial stroma. Weaker dark brown staining was observed in the four treatment groups compared with the control group. C: Controls; T: testosterone; FLU: flutamide; FIN: finasteride; ANA: anastrozole; S: Stroma Scale bar=2000 $\mu m$. Magnification $100 \times$ and $400 \times, n=6$ per group.

during the pre-implantation period was recognized as a marker for a non-receptive endometrium (17). Treatment with a progesterone antagonist, was found to reverse the suppression of connexin expression during early pregnancy (18), thus disrupting embryo implantation in rats (25). Therefore, treatment with a high dose of testosterone could interfere with the uterine receptivity regulation, thus leading to implantation failure.

It has been reported that the expression of connexin 43 in the rat uterus is suppressed during the uterine receptivity period (8), however other studies have reported contradictory results. Jahn, et al. (9) have reported that connexin 43 
expression was reduced during the uterine receptivity period, while Granot, et al. (26) showed an increased expression of this gene in the human endometrium. The definite role of connexin 43 in the receptive state of the endometrium has not been explained yet. However, induction of connexin 43 during decidualization in rats (8), has been reported to be crucial for the differentiation of stromal cells into decidua, as well as for angiogenesis (27). Also, the expression of connexin 43 in patients with recurrent early pregnancy losses was found to be reduced (28). Besides, anti-malarial medication, mefloquine, which is a potent blocker of connexin 43, is associated with an increased risk of spontaneous abortion (29). In this study, the distribution of connexin 43 was detected in the endometrial stromal, which is in line with other studies (8). Following treatment with a high concentration of testosterone, it was found that the expression and distribution of connexin 43 in the uterus were suppressed; this aberrant expression of connexins may contribute to the loss of intercellular communication via gap junctions (30) and might hinder the transformation of stromal cells into a receptive endometrium, and could thus lead to early pregnancy loss.

It has been reported that testosterone can be converted into dihydrotestosterone and estrogen by the action of $5 \alpha$-reductase and the aromatase enzyme, respectively (31-33). In this study, no significant difference was recorded on the expression of connexin 26 and connexin 43 genes among the groups treated with testosterone and those treated with testosterone and finasteride or anastrozole. This indicates that the effect of testosterone on connexin 26 and connexin 43 gene expression did not involve dihydrotestosterone and estrogen. Our finding is consistent with the previous study, which revealed that testosterone treatment reduces the expression of av $\beta 3$-Integrin, E-Cadherin, and Mucin-1 in the endometrium of rats during the uterine receptivity period, however, this effect did not involve dihydrotestosterone (19). In addition, Gibson, et al. (34) studied the expression and activity of $5 \alpha$-reductase in endometrial stromal cells (ESCs) and reported that although the $5 \alpha$-reductase protein was present in these cells, dihydrotestosterone could only be detected in the decidualization stage. Besides, it has been shown that the aromatase enzyme does not affect the protective effects of testosterone on the rat bone as the results from the testosterone treatment group did not differ to those in the testosterone cotreated with anastrozole treatment group (35). Furthermore, a study by Labrie (36) showed that the aromatase enzyme cannot be detected in the endometrium of women undergoing regular cycles. It is therefore suggested that the changes in expression of connexin 26 and connexin 43 genes were due to the effects of testosterone alone, without being influenced by its conversion to dihydrotestosterone or estrogen.

Flutamide, an androgen receptor (AR) blocker, reversed the effect of testosterone on the expression of both connexin 26 and connexin 43 . This shows that the androgen receptor plays a role in the action of testosterone. This finding was consistent with the results of another study that showed the treatment with flutamide altered connexin 43 expression in the pig's uterus (37). Similarly, another study has reported that testosterone reduced the expression of pinopodes and MECA79 , which are markers of a receptive endometrium and that testosterone effects were abolished by flutamide (22). Furthermore, AR could be detected in the rat uterus (38), and the expression was increased with increasing testosterone concentration (39). These findings strengthen the relation of AR to the mechanism of action of testosterone in the rat uterus. Even in the human endometrium, AR is known to be expressed in the endometrial stroma during the proliferative phase, while in the secretory phase, AR is primarily expressed in the uterine epithelial cells (40).

\section{Conclusion}

In conclusion, treatment with a high dose of testosterone increased connexin 26 expression and protein distribution while decreased connexin 43 expression and protein distribution in the uterus during early pregnancy. The altered physiological expression of connexins during uterine receptivity related to the high concentration of testosterone such as in polycystic ovarian disease (PCO) or following excessive anabolic steroids might interfere with the embryo implantation thus lead to early pregnancy loss.

\section{Conflicts of Interest}

The Authors declare no conflicts of interest associated with this research.

\section{Authors' Contributions}

M.H.M designed the research. D.A.M.K collected tissue samples and performed experiments. S.F.I, M.H.M and D.A.M.K wrote the manuscript. M.H.M and S.F.I supervised the research.

\section{Acknowledgements}

The Authors acknowledge the financial support from National University of Malaysia (UKM) Geran Galakan Penyelidik Muda (GGPM-2017-045).

\section{References}

1 Lu Q, Shen H, Li Y, Zhang C, Wang C, Chen X, Liang R and Wei L: Low testosterone levels in women with diminished ovarian reserve impair embryo implantation rate: A retrospective case-control study. J Assist Reprod Genet 31(4): 485-491, 2014. PMID: 24526354. DOI: 10.1007/s10815-014-0186-3

2 Cloke B and Christian M: The role of androgens and the androgen receptor in cycling endometrium. Mol Cell Endocrinol 
358(2): 166-175, 2012. PMID: 21745536. DOI: 10.1016/j.mce. 2011.06 .031

3 Diao HL, Su RW, Tan HN, Li SJ, Lei W, Deng WB and Yang ZM: Effects of androgen on embryo implantation in the mouse delayed-implantation model. Fertil Steril 90(4 Suppl): 13761383, 2008. PMID: 18053999. DOI: 10.1016/j.fertnstert. 2007.07.1341

4 Wang $\mathrm{H}$ and Dey SK: Roadmap to embryo implantation: Clues from mouse models. Nat Rev Genet 7(3): 185-199, 2006. PMID: 16485018. DOI: $10.1038 / \mathrm{nrg} 1808$

5 Revel A: Defective endometrial receptivity. Fertil Steril 97(5): 1028-1032, 2012. PMID: 22542142. DOI: 10.1016/j.fertnstert. 2012.03.039

6 Paulson RJ: Hormonal induction of endometrial receptivity. Fertil Steril 96(3): 530-535, 2011. PMID: 21880274. DOI: 10.1016/j.fertnstert.2011.07.1097

7 Grummer R, Reuss B and Winterhager E: Expression pattern of different gap junction connexins is related to embryo implantation. Int J Dev Biol 40(1): 361-367, 1996. PMID: 8735949.

8 Winterhager E, Grummer R, Jahn E, Willecke K and Traub O: Spatial and temporal expression of connexin 26 and connexin 43 in rat endometrium during trophoblast invasion. Dev Biol 157(2): 399-409, 1993. PMID: 8388816. DOI: 10.1006/dbio. 1993.1144

9 Jahn E, Classen-Linke I, Kusche M, Beier HM, Traub O, Grummer R and Winterhager E: Expression of gap junction connexins in the human endometrium throughout the menstrual cycle. Hum Reprod 10(10): 2666-2670, 1995. PMID: 8567789. DOI: 10.1093/oxfordjournals.humrep.a135764

10 Saito T, Oyamada M, Yamasaki H, Mori M and Kudo R: Coordinated expression of connexins 26 and 32 in human endometrial glandular epithelium during the reproductive cycle and the influence of hormone replacement therapy. Int J Cancer 73(4): 479-485, 1997. PMID: 9389559. DOI: 10.1002/ (sici)1097-0215(19971114)73:4<479::aid-ijc4>3.0.co;2-x

11 Winterhager E and Kidder GM: Gap junction connexins in female reproductive organs: Implications for women's reproductive health. Hum Reprod Update 21(3): 340-352, 2015. PMID: 25667189. DOI: 10.1093/humupd/dmv007

12 Kumar NM and Gilula NB: The gap junction communication channel. Cell 84(3): 381-388, 1996. PMID: 8608591. DOI: $10.1016 / \mathrm{s} 0092-8674(00) 81282-9$

13 Mese G, Richard G and White TW: Gap junctions: Basic structure and function. J Invest Dermatol 127(11): 2516-2524, 2007. PMID: 17934503 . DOI: $10.1038 /$ sj.jid.5700770

14 Harris AL and Contreras JE: Motifs in the permeation pathway of connexin channels mediate voltage and ca (2+) sensing. Front Physiol 5: 113, 2014. PMID: 24744733. DOI: 10.3389/fphys. 2014.00113

15 Bruzzone R, White TW and Paul DL: Connections with connexins: The molecular basis of direct intercellular signaling. In: Ejb reviews 1996. Christen P and Hofmann E (eds.). Springer Berlin Heidelberg: Berlin, Heidelberg, pp. 135-161, 1997.

16 Kibschull M, Gellhaus A, Carette D, Segretain D, Pointis G and Gilleron J: Physiological roles of connexins and pannexins in reproductive organs. Cell Mol Life Sci 72(15): 2879-2898, 2015. PMID: 26100514. DOI: 10.1007/s00018-015-1965-4

17 Grummer R, Chwalisz K, Mulholland J, Traub $\mathrm{O}$ and Winterhager E: Regulation of connexin 26 and connexin 43 expression in rat endometrium by ovarian steroid hormones. Biol Reprod 51(6): 1109-1116, 1994. PMID: 7888490. DOI: 10.1095/biolreprod51.6.1109

18 Grummer R and Winterhager E: Regulation of gap junction connexins in the endometrium during early pregnancy. Cell Tissue Res 293(2): 189-194, 1998. PMID: 9662642. DOI: $10.1007 / \mathrm{s} 004410051111$

19 Mohd Mokhtar H, Giribabu N and Salleh N: Testosterone down-regulates expression of $\alpha v \beta 3$-integrin, e-cadherin and mucin-1 during uterine receptivity period in rats. Sains Malaysiana 47(10): 2509-2517, 2018. DOI: 10.17576/jsm-20184710-28

20 Akpak YK, Cekmez Y, Erdogan Cakir A, Karaca N, Batmaz G, Gulsen S and Tustas Haberal E: An animal model of effects of nicotine exposure on endometrial receptivity and embryo implantation in pregnancy. J Matern Fetal Neonatal Med 30(23): 2818-2823, 2017. PMID: 27884089. DOI: 10.1080/14767058. 2016.1265499

21 Dehghan F, Muniandy S, Yusof A and Salleh N: Sex-steroid regulation of relaxin receptor isoforms (rxfp1 \&amp; rxfp2) expression in the patellar tendon and lateral collateral ligament of female wky rats. Int J Med Sci 11(2): 180-191, 2014. PMID: 24465164. DOI: 10.7150/ijms.6283

22 Mokhtar HM, Giribabu N, Muniandy S and Salleh N: Testosterone decreases the expression of endometrial pinopode and 1-selectin ligand (meca-79) in adult female rats during uterine receptivity period. Int J Clin Exp Pathol 7(5): 1967-1976, 2014. PMID: 24966906.

23 Moradpour F, Naghdi N and Fathollahi Y: Anastrozole improved testosterone-induced impairment acquisition of spatial learning and memory in the hippocampal cal region in adult male rats. Behav Brain Res 175(2): 223-232, 2006. PMID: 17018237. DOI: 10.1016/j.bbr.2006.08.037

24 Risek B, Klier FG, Phillips A, Hahn DW and Gilula NB: Gap junction regulation in the uterus and ovaries of immature rats by estrogen and progesterone. J Cell Sci 108 (Pt 3): 1017-1032, 1995. PMID: 7622591.

25 Roblero LS and Croxatto HB: Effect of ru486 on development and implantation of rat embryos. Mol Reprod Dev 29(4): 342 346, 1991. PMID: 1888514. DOI: 10.1002/mrd.1080290405

26 Granot I, Dekel N, Bechor E, Segal I, Fieldust S and Barash A: Temporal analysis of connexin 43 protein and gene expression throughout the menstrual cycle in human endometrium. Fertil Steril 73(2): 381-386, 2000. PMID: 10685547. DOI: 10.1016/ s0015-0282(99)00531-2

27 Grund S and Grümmer R: Direct cell-cell interactions in the endometrium and in endometrial pathophysiology. Int J Mol Sci 19(8): 2227, 2018. DOI: 10.3390/ijms19082227

28 Nair RR, Jain M and Singh K: Reduced expression of gap junction gene connexin 43 in recurrent early pregnancy loss patients. Placenta 32(8): 619-621, 2011. PMID: 21669459. DOI: 10.1016/j.placenta.2011.05.010

29 Nevin RL: Mefloquine blockade of connexin 43 (cx43) and risk of pregnancy loss. Placenta 32(9): 712, 2011. PMID: 21764445. DOI: $10.1016 /$ j.placenta.2011.06.016

30 Radic J, Kruslin B, Samija M, Ulamec M, Milosevic M, Jazvic M, Samija I, Grah JJ, Bolanca A and Kusic Z: Connexin 43 expression in primary colorectal carcinomas in patients with stage iii and iv disease. Anticancer Res 36(5): 2189-2196, 2016. PMID: 27127122. 
31 Berman JR, Almeida FG, Jolin J, Raz S, Chaudhuri G and Gonzalez-Cadavid NF: Correlation of androgen receptors, aromatase, and 5- $\alpha$ reductase in the human vagina with menopausal status. Fertil Steril 79(4): 925-931, 2003. DOI: 10.1016/s0015-0282(02)04923-3

32 Ohsako S, Miyabara Y, Nishimura N, Kurosawa S, Sakaue M, Ishimura R, Sato M, Takeda K, Aoki Y, Sone H, Tohyama C and Yonemoto J: Maternal exposure to a low dose of 2,3,7,8tetrachlorodibenzo-p-dioxin (tcdd) suppressed the development of reproductive organs of male rats: Dose-dependent increase of mrna levels of 5alpha-reductase type 2 in contrast to decrease of androgen receptor in the pubertal ventral prostate. Toxicol Sci 60(1): 132-143, 2001. PMID: 11222880. DOI: 10.1093/toxsci/ 60.1 .132

33 Roselli CE, Cross E, Poonyagariyagorn HK and Stadelman HL: Role of aromatization in anticipatory and consummatory aspects of sexual behavior in male rats. Horm Behav 44(2): 146-151, 2003. PMID: 13129487. DOI: 10.1016/s0018-506x(03)00123-5

34 Gibson DA, Simitsidellis I, Cousins FL, Critchley HO and Saunders PT: Intracrine androgens enhance decidualization and modulate expression of human endometrial receptivity genes. Sci Rep 6: 19970, 2016. PMID: 26817618. DOI: 10.1038/srep19970

35 Beck DT, Yarrow JF, Beggs LA, Otzel DM, Ye F, Conover CF, Miller JR, Balaez A, Combs SM, Leeper AM, Williams AA, Lachacz SA, Zheng N, Wronski TJ and Borst SE: Influence of aromatase inhibition on the bone-protective effects of testosterone. J Bone Miner Res 29(11): 2405-2413, 2014. PMID: 24764121. DOI: $10.1002 / \mathrm{jbmr} .2265$
36 Labrie F: All sex steroids are made intracellularly in peripheral tissues by the mechanisms of intracrinology after menopause. J Steroid Biochem Mol Biol 145: 133-138, 2015. PMID: 24923731. DOI: 10.1016/j.jsbmb.2014.06.001

37 Wieciech I, Grzesiak M, Knapczyk-Stwora K, Pytlik A and Slomczynska M: Influence of the antiandrogen flutamide on connexin 43 (cx43) gene and protein expression in the porcine placenta and uterus during pregnancy. Folia Biol (Krakow) 62(4): 367-375, 2014. PMID: 25916165. DOI: 10.3409/ fb62_4.367

38 Hirai M, Hirata S, Osada T, Hagihara K and Kato J: Androgen receptor mrna in the rat ovary and uterus. J Steroid Biochem Mol Biol 49(1): 1-7, 1994. PMID: 8003434. DOI: 10.1016/09600760(94)90294-1

39 Kyriakidis I, Dermentzopoulou-Theodoridou M, Papamitsou T, Makaronidis I, Tsanakalis F, Manthos A and Papaioannidou P: Immunohistochemical study of androgen receptors in rat uterus after administration of testosterone. Front Pharmacol, 2010. DOI: 10.3389/conf.fphar.2010.60.00152

40 Ito K, Suzuki T, Akahira J, Moriya T, Kaneko C, Utsunomiya H, Yaegashi N, Okamura K and Sasano H: Expression of androgen receptor and 5alpha-reductases in the human normal endometrium and its disorders. Int J Cancer 99(5): 652-657, 2002. PMID: 12115497. DOI: 10.1002/ijc.10394

Received March 26, 2020

Revised April 1, 2020

Accepted April 2, 2020 